\title{
Predicting the $F(a b)$-mediated effect of monoclonal antibodies in vivo by combining cell-level kinetic and pharmacokinetic modelling
}

\author{
Ben-Fillippo Krippendorff • Diego A. Oyarzún • \\ Wilhelm Huisinga
}

Received: 11 July 2011 / Accepted: 9 February 2012/Published online: 8 March 2012

(c) The Author(s) 2012. This article is published with open access at Springerlink.com

\begin{abstract}
Cell-level kinetic models for therapeutically relevant processes increasingly benefit the early stages of drug development. Later stages of the drug development processes, however, rely on pharmacokinetic compartment models while cell-level dynamics are typically neglected. We here present a systematic approach to integrate celllevel kinetic models and pharmacokinetic compartment models. Incorporating target dynamics into pharmacokinetic models is especially useful for the development of therapeutic antibodies because their effect and pharmacokinetics are inherently interdependent. The approach is illustrated by analysing the $\mathrm{F}(\mathrm{ab})$-mediated inhibitory effect of therapeutic antibodies targeting the epidermal growth factor receptor. We build a multi-level model for anti-EGFR antibodies by combining a systems biology model with in vitro determined parameters and a pharmacokinetic model based on in vivo pharmacokinetic data. Using this model, we investigated in silico the impact of biochemical properties of anti-EGFR antibodies on their $\mathrm{F}(\mathrm{ab})$-mediated inhibitory effect. The multi-level model
\end{abstract}

\section{B.-F. Krippendorff $(\square)$}

Pharmacology \& Drug Development Group, Department of Oncology, Cancer Research UK Cambridge Research Institute, Li Ka Shing Centre, University of Cambridge, Cambridge CB2 ORE, UK

e-mail: bfk22@cam.ac.uk

D. A. Oyarzún

Centre for Synthetic Biology and Innovation, Department of Bioengineering, Imperial College London,

London SW7 2AZ, UK

\section{W. Huisinga}

Institut für Mathematik, Universität Potsdam, Wissenschaftspark Golm, 14476 Potsdam, Germany

e-mail: huisinga@unipotsdam.de suggests that the $F(a b)$-mediated inhibitory effect saturates with increasing drug-receptor affinity, thereby limiting the impact of increasing antibody affinity on improving the effect. This indicates that observed differences in the therapeutic effects of high affinity antibodies in the market and in clinical development may result mainly from Fcmediated indirect mechanisms such as antibody-dependent cell cytotoxicity.

Keywords Cell-level kinetics · Pharmacokinetic models · Therapeutic proteins $\cdot$ EGFR

\section{Introduction}

Biotechnologically engineered proteins such as monoclonal antibodies (mAbs) have demonstrated their potential in therapies for cancer and other complex diseases [1]. Due to their ability to specifically bind targets, they allow to modulate specific cellular targets and signaling pathways. Various therapeutic proteins on the market use their binding specificity to inhibit cell surface receptors with critical biologic function. At the same time, many targeted receptor systems also constitute a degradation mechanism for such drugs because binding leads to endocytosis and ultimately degradation of the drug. A thorough understanding of the complex interplay between a drug's pharmacokinetics and its effect is largely missing.

Empirical or semi-mechanistic compartmental models are typically used to analyze preclinical or clinical pharmacokinetic data of protein drugs [2-6]. In these models, the interaction of the drug with its target is represented by an empirical or semi-mechanistic term, accounting for the saturable degradation capacity of the target system. Further, models of target mediated drug disposition (TMDD) 
have been proposed as a general semi-mechanistic model for drugs that bind with high affinity and to a significant extent to a pharmacologic target such as an enzyme, receptor, or transporter [7-9]. This is accomplished by describing the target as an additional binding compartment.

In systems biology, detailed mechanistic models of targets at the cell level have proven valuable for identifying potent drug targets [10]. Such mathematical models allow identifying and ranking potential targets in cellular networks for achieving specific downstream effects [11, 12]. A recent prominent example is the use of a kinetic model to identify critical components in ErbB signaling pathways [13] and was the basis for the development of a therapeutic antibody that targets the ErbB3 receptor and is currently in Phase II clinical trials [14].

Linking pharmacokinetic and systems biology modelling approaches allows a multi-level description of the system as a whole. These kinds of systems pharmacology models are therefore increasingly advocated by researchers as well as regulators [15]. A combined model for a drugs' pharmacokinetic and its cellular effect would be especially valuable for therapeutic proteins where drug effect and pharmacokinetics are inherently interdependent. As models of both, whole-body pharmacokinetics and cellular target dynamics, are becoming more abundant, the main bottleneck in developing multi-level systems pharmacology models is in how to interface the cellular and whole body layers levels.

The objective of this article is to develop a systematic approach to integrate the cellular-level into compartment models of drug pharmacokinetics. Due to their important role in the treatment of cancer, we have developed a celllevel pharmacokinetic/pharmacodynamic model for antibodies antagonistically inhibiting the epidermal growth factor receptor (EGFR). The binding of one of its natural ligands to the EGFR results in the activation of signal transduction pathways that mediate a variety of cellular responses [16] which include cell proliferation, differentiation, survival, and angiogenesis [17]. We illustrate our approach by developing a cell-level PK/PD model for the anti-EGFR therapeutic antibody zalutumumab in cynomolgus monkeys. The model integrates a compartment model developed based on in vivo plasma data for zalutumumab [6], and a receptor trafficking model based on in vitro data of the EGFR [18-24].

mAbs comprise a variable target-specific $\mathrm{F}(\mathrm{ab})$ region and aconstant Fc region [4]. The target-specific part recognizes the targeted protein, whereas the constant part is involved in different mechanism which determine the pharmacokinetics as well as trigger indirect therapeutic effects such as triggering antibody-dependent cell cytotoxicity. Using our combined model and integrating preclinical pharmacokinetic data we have investigated in silico the impact of biochemical properties of anti-EGFR antibodies on the $F(a b)$-mediated inhibitory effect. This new kind of model allows to identify in silico opportunities and limitations for the optimization of biophysical properties of future therapeutic antibodies.

\section{Theoretical}

Compartment model of in vivo therapeutic antibody pharmacokinetics

The pharmacokinetic part of the multi-level model will be based on Zalutumumab (2F8), an IgG1 antibody against EGFR that inhibits tumor growth in xenograft models and has shown promising results in phase I/II clinical trials [25, 26]. Lammerts van Bueren et al. [6] developed a 3-compartment pharmacokinetic model of zalutumumab in cynomolgus monkeys which accurately describes experimental plasma data for high and low doses (Fig. 1a). In the model, $C_{\text {pla }}$ and $C_{\text {int }}$ represent the concentrations of the $\mathrm{mAb}$ in plasma (with volume $V_{\text {pla }}$ ) and the interstitial space (with volume $V_{\text {int }}$ ). $A_{\mathrm{RS}}$ denotes the amount of drug that is bound to the targeted receptor. The parameters $q_{\mathrm{pi}}$ and $q_{\mathrm{ip}}$ denote the transfer flows between the plasma and interstitial compartment, $k_{\mathrm{b}}$ denotes some large 'artificial' rate constant that ensures quasi-steady state conditions between the unbound drug concentration in the interstitial space and the drug bound to the receptor. The amount of drug bound to the receptor is modeled in terms of a Michaelis Menten term with $B_{\max }$ PK denoting the maximal binding capacity of the therapeutic protein to EGFR and $K_{\mathrm{M}, \mathrm{PK}}$ denoting the concentration corresponding to the half-maximal binding capacity. The rate constant of elimination of EGFR by internalization and degradation is denoted by $k_{\mathrm{el}}$, while the target-independent clearance such as proteolysis in the blood [27] is denoted by $\mathrm{CL}_{\mathrm{lin}}$. The values of the parameters as used by Lammerts van Bueren et al. are given in Table 1. The rate of change of the molecular concentrations and amount is given by: ${ }^{1}$

$V_{\mathrm{pla}} \frac{\mathrm{d} C_{\mathrm{pla}}}{\mathrm{d} t}=-q_{\mathrm{pi}} C_{\mathrm{pla}}+q_{\mathrm{ip}} C_{\mathrm{int}}-\mathrm{CL}_{\mathrm{lin}} \cdot C_{\mathrm{pla}}$

\footnotetext{
1 We transformed the originally published system of difference equations [6, Supplement] into a corresponding continuous system of ordinary differential equations. The originally published equations in [6, Supplement] are identical to a certain discretization of the system of ODEs (1-3). The advantage of stating the system as continuous ODEs is that subsequently any numerical scheme can be used to solve them, in particular high accuracy ODE solver with adaptive step size control. See also [28].
} 
Fig. 1 Schematic illustration of the pharmacokinetic model and the kinetic cell-level model. a Semi-mechanistic pharmacokinetic compartment model describing the pharmacokinetics of the the $\mathrm{mAb}$ zalutumumab in monkeys developed by Lammerts van Bueren et al. [6]. b Canonical model of ligand-receptor activation and trafficking $[19,29,20]$
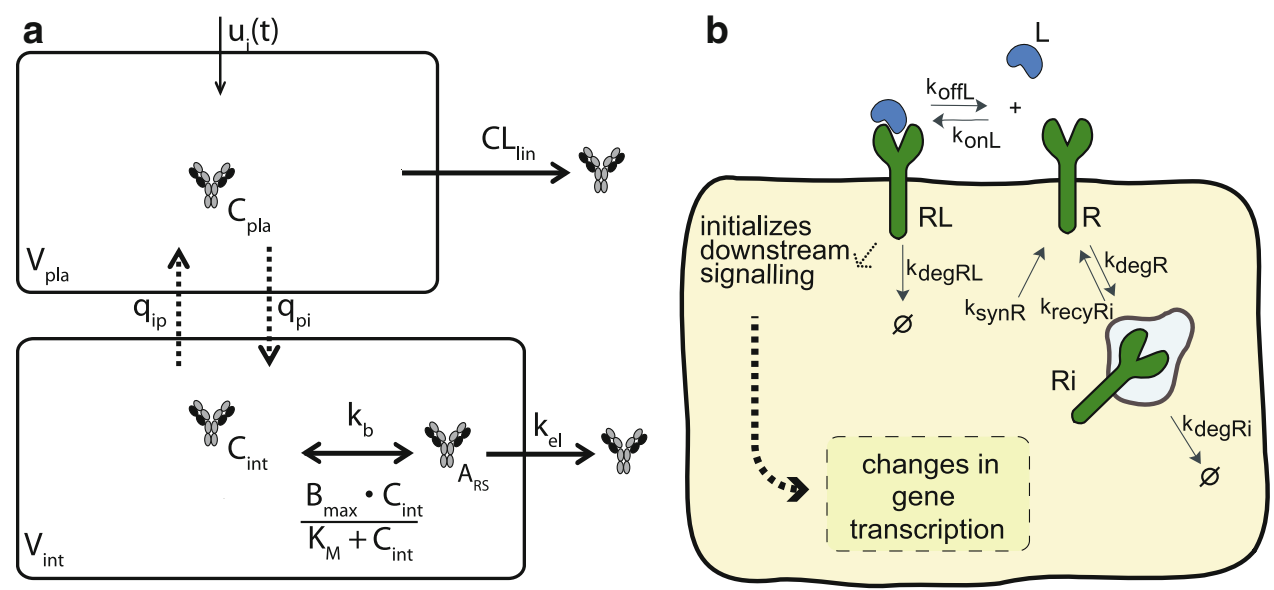

Table 1 Pharmacokinetic parameters determined in vivo by Lammerts van Bueren et al. [16]

\begin{tabular}{|c|c|c|c|}
\hline Name & Definition & Value & Unit \\
\hline$V_{\text {pla }}$ & Plasma volume & 70 & $\mathrm{ml} / \mathrm{kg}$ \\
\hline$V_{\text {int }}$ & Interstitial volume & 35 & $\mathrm{ml} / \mathrm{kg}$ \\
\hline$k_{\mathrm{pi}}$ & $\begin{array}{l}\text { Rate constant of plasma-interstitial } \\
\text { transport }\end{array}$ & 0.043 & $1 / \mathrm{h}$ \\
\hline$k_{\text {ip }}$ & $\begin{array}{l}\text { Rate constant of interstitial-plasma } \\
\text { transport }\end{array}$ & 0.043 & $1 / \mathrm{h}$ \\
\hline $\mathrm{k}_{\mathrm{b}}$ & $\begin{array}{l}\text { Constant thatensures quasi-steady } \\
\text { state conditions }\end{array}$ & 0.069 & $1 / \mathrm{h}$ \\
\hline$B_{\max , \mathrm{PK}}$ & Whole-body capacity & 2 & $\mathrm{mg} / \mathrm{h} / \mathrm{kg}$ \\
\hline$K_{\mathrm{M}, \mathrm{PK}}$ & $\begin{array}{l}\text { Half-maximal binding capacity in } \\
\text { vivo }\end{array}$ & $0.5 \cdot 10^{-3}$ & $\mathrm{mg} / \mathrm{ml}$ \\
\hline $\mathrm{k}_{\mathrm{el}}$ & $\begin{array}{l}\text { Elimination of EGFR by } \\
\text { internalization and degradation }\end{array}$ & 0.0055 & $1 / \mathrm{h}$ \\
\hline$q_{\mathrm{pi}}$ & Plasma-interstitial transport & $V_{\mathrm{pla}} \cdot k_{\mathrm{pi}}$ & $\mathrm{ml} / \mathrm{h}$ \\
\hline$q_{\mathrm{ip}}$ & Interstitial-plasma transport & $V_{\text {int }} \cdot k_{\text {ip }}$ & $\mathrm{ml} / \mathrm{h}$ \\
\hline $\mathrm{CL}_{\text {lin }}$ & Target-independent drug clearance & $V_{\mathrm{pla}} \cdot \mathrm{k}_{\mathrm{el}}$ & $\mathrm{ml} / \mathrm{h} / \mathrm{kg}$ \\
\hline
\end{tabular}

Units were converted from $\mathrm{mg}$ to nmol using the scaling factor $\mathrm{SF}_{\mathrm{mg} \rightarrow \mu \mathrm{mol}}=10^{6} / \mathrm{MW}_{\mathrm{mAbs}}$ with MW_\{mAbs $=148000 \mathrm{~g} / \mathrm{mol}$, i.e., $1 \mathrm{mg}=\mathrm{SF}_{\mathrm{mg} \rightarrow \mu \mathrm{mol}} \cdot \mathrm{nmol}$

$V_{\mathrm{int}} \frac{\mathrm{d} C_{\mathrm{int}}}{\mathrm{d} t}=+q_{\mathrm{pi}} C_{\mathrm{pla}}-q_{\mathrm{ip}} C_{\mathrm{int}}-k_{b}\left(\frac{B_{\mathrm{max}, \mathrm{PK}} \cdot C_{\mathrm{int}}}{K_{\mathrm{M}, \mathrm{PK}}+C_{\mathrm{int}}}-A_{\mathrm{RS}}\right)$

$\frac{\mathrm{d} A_{\mathrm{RS}}}{\mathrm{d} t}=k_{b}\left(\frac{B_{\mathrm{max}, \mathrm{PK}} \cdot C_{\mathrm{int}}}{K_{\mathrm{M}, \mathrm{PK}}+C_{\mathrm{int}}}-A_{\mathrm{RS}}\right)-k_{\mathrm{el}} A_{\mathrm{RS}}$

In the above model of Lammerts van Bueren et al., the interaction of zalutumumab with its target (represented by the Michaelis Menten term) accounts for the non-linear feedback of the receptor system on the $\mathrm{mAb}$ concentration in the interstitial space, known as receptor mediated endocytosis. With regard to drug effect, the above model does not allow us, however, to analyze the inhibitory effect of zalutumumab on the targeted receptors. Moreover, the Michaelis Menten interaction term is a hybrid parameter in the sense that it combines drug related properties - like binding and dissociation rate constants as well as internalisation rate constants- with receptor system parameters-like receptor synthesis, degradation and internalization [28]. As a consequence, the parameters $B_{\max \text { PK }}$ and $K_{\mathrm{M}, \mathrm{PK}}$ are specific to zalutumuab. An analysis of the impact of changes in the drug-receptor interaction is not feasible with this model, nor is the study of the impact of different cell types, like normal and tumor cells, on the PK and PD of the therapeutic antibody. Both tasks, however, are feasible at the single cell level using kinetic models of the targeted receptor system.

Kinetic model of in vitro ligand-receptor interaction

To describe the cell-level kinetics we use a canonical model of ligand-receptor activation and trafficking [19, 29, 20] which is parameterized using rate constants that have been experimentally determined and validated in human fibroblast cells [29, 20] (Fig. 1b). The molecular species $R, R_{\mathrm{i}}, L$ and $R L$ denote the numbers of free receptors, free internalized receptors, free extracellular ligand and ligandreceptor complexes per cell, respectively. In the model, the ligand $L$ reversibly binds to the free receptors with association rate constant $k_{\mathrm{onL}}$, and dissociate with rate constant $k_{\text {offL }}$. The free membrane receptors $R$ are internalized with rate constant $k_{\mathrm{degR}}$ and recycled with rate constant $k_{\text {recyRi }}$ or degraded with rate constant $k_{\text {degRi }}$. The ligand-receptor complex is internalized with rate constant $k_{\text {degRL }}$. The rate of change of the different molecular species is given by: $\frac{\mathrm{d} R}{\mathrm{~d} t}=k_{\mathrm{synR}}-k_{\mathrm{onL}} R \cdot L+k_{\mathrm{offL}} \cdot R L-k_{\mathrm{degR}} \cdot R+k_{\mathrm{recyRi}} \cdot R_{\mathrm{i}}$

$\frac{\mathrm{d} R_{\mathrm{i}}}{\mathrm{d} t}=k_{\mathrm{degR}} \cdot R-k_{\mathrm{recyRi}} \cdot R_{\mathrm{i}}-k_{\mathrm{degRi}} \cdot R_{\mathrm{i}}$

$\frac{\mathrm{d} R L}{\mathrm{~d} t}=k_{\mathrm{onL}} R \cdot L-k_{\mathrm{offL}} R L-k_{\mathrm{degRL}} R L$.

All molecular species are in number of molecules per cell, except $L$ which is in molar concentration. An EGF concentration of $L=2.36 \cdot 10^{-3} \mathrm{nM}$ was assumed [30]. 
The model of ligand-receptor interaction can easily be extended to account for the drug-receptor interaction by including reactions for drug-receptor association and dissociation (with rate constants $k_{\mathrm{onC}}$ and $k_{\mathrm{offC}}$ ) as well as internalization and subsequent degradation of the drugreceptor complex (with effective rate constant $k_{\text {degRC }}$ ), see Fig. 2a. The extended cell-level model including the therapeutic antibody $C_{\mathrm{ex}}[\mathrm{in}(\mathrm{nM})]$ in the extra-cellular space with volume $V_{\mathrm{ex}}$, and the drug-receptor complex $R C$ [in (\#molecules)] is given by:

$$
\begin{aligned}
& V_{\mathrm{ex}} \frac{\mathrm{d} C_{\mathrm{ex}}}{\mathrm{d} t}=k_{\mathrm{offC}} \cdot \mathrm{SF}_{\mathrm{unit}} \cdot \mathrm{RC}-\mathrm{k}_{\mathrm{onC}} \cdot \mathrm{SF}_{\text {unit }} \cdot \mathrm{R} \cdot \mathrm{C}_{\mathrm{ex}} \\
& \frac{\mathrm{d} R}{\mathrm{~d} t}=k_{\mathrm{synR}}-k_{\mathrm{onL}} R \cdot L-k_{\mathrm{onC}} R \cdot C_{\mathrm{ex}}+k_{\mathrm{offL}} R L+k_{\mathrm{offC}} R C \\
& -k_{\mathrm{degR}} \cdot R+k_{\mathrm{recyRi}} \cdot R_{\mathrm{i}} \\
& \frac{\mathrm{d} R_{\mathrm{i}}}{\mathrm{d} t}=k_{\mathrm{degR}} \cdot R-k_{\mathrm{recyRi}} \cdot R_{\mathrm{i}}-k_{\mathrm{degRi}} \cdot R_{\mathrm{i}} \\
& \frac{\mathrm{d} R L}{\mathrm{~d} t}=k_{\mathrm{onL}} \cdot L \cdot R-k_{\mathrm{offL}} R L-k_{\mathrm{degRL}} R L \\
& \frac{\mathrm{d} R C}{\mathrm{~d} t}=k_{\mathrm{onC}} \cdot C_{\mathrm{ex}} \cdot R-k_{\mathrm{offC}} R D-k_{\mathrm{degRC}} \cdot R C
\end{aligned}
$$

where the $\mathrm{SF}_{\text {unit }}=10^{9} / N_{\mathrm{avog}}$ denotes a scaling factor from [\#molecules] to [nmol] with $N_{\text {avo }}=6.02 \cdot 10^{23} 1 /$ mol denoting Avogardo's constant. We included those biological processes which are expected to have an impact on the PK of the drug and provide a possibility to link detailed systems biology model of downstream signalling pathway.

To study the inhibitory potential of a therapeutic antibody on a signalling pathway, realistic time-dependent concentration time profiles are essential. As discussed, for many therapeutic antibodies, the targeted system also has an influence on the time-course of the antibody via receptor mediated drug uptake and degradation. Hence, not only has the drug an effect on the receptor system, but also does the receptor system impact on the pharmacokinetics of the drug. As a consequence, we herein propose a novel approach based on integrating the single-cell level into compartment models of antibody PK.

\section{Linking whole-body and single-cell level}

On the whole-body level, the interaction of zalutumumab with its target is represented by a Michaelis Menten term that describes the apparent drug-receptor interactions. At the cellular level, this apparent interaction comprises several kinetic processes, including association and dissociation of the drug-receptor complex, internalization and subsequent degradation of the internalized drug-receptor complex. The assumption underlying our approach is that the apparent drug-receptor interaction on the whole-body level collectively represents the drug-receptor interaction of all relevant cells at the cellular level, i.e., all targetexpressing cells that are exposed to the drug. The idea is then to replace the apparent drug-receptor interaction in the compartment model (1-3) by the detailed cell-level model (7-11), scaled from the single-cell to the wholebody level with the number of relevant cells. As a result of this integration process, we obtained a cell-level PK/ PD model that allowed us to study the pharmacokinetics on the whole-body level and at the same time the inhibitory effect on the cellular level. For the integration, we determined (i) the apparent drug-receptor interaction of a single cell; and (ii) number of all relevant cells $N_{\text {cell }}$ as the scaling factor that links the apparent drug-receptor interaction of a single-cell to the apparent drug-receptor interaction of the whole-body level.

The apparent drug-receptor interactions of a single cell was determined as the reduced description of the cellular model (7-11) using the quasi-steady state assumption on the receptor species $R, R_{\mathrm{i}}, R L$ and $R C$ (see, e.g, [28] for illustrative examples). This resulted in the reduced model for the extra-cellular drug concentration $C_{\mathrm{ex}}$, the membrane-bound amount of $\operatorname{drug} A_{\mathrm{RS}}$ and the total drug concentration $C_{\mathrm{tot}}=C_{\mathrm{ex}}+A_{\mathrm{RS}} / V_{\mathrm{ex}}$, where $V_{\text {ex }}$ denotes the extra-cellular volume associated with a single cell:

$V_{\mathrm{ex}} \frac{\mathrm{d} C_{\mathrm{tot}}}{\mathrm{d} t}=-k_{\mathrm{degRC}} \cdot \underbrace{\frac{B_{\mathrm{max}, \text { cell }} \cdot C_{\mathrm{ex}}}{K_{\mathrm{M}, \text { cell }}+C_{\mathrm{ex}}}}_{A_{\mathrm{RS}}}$

$C_{\mathrm{ex}}=\frac{1}{2}\left(C_{D}+\sqrt{\left(C_{D}\right)^{2}+4 K_{\mathrm{M}, \mathrm{cell}} C_{\mathrm{tot}}}\right)$

with $C_{D}=C_{\text {tot }}-\left(B_{\text {max,cell }} / V_{\text {ex }}\right)-K_{\mathrm{M} \text {,cell. }}$ The parameters $B_{\text {max,cell }}$ and $K_{\mathrm{M} \text {,cell }}$ denote the maximal binding capacity of a single cell and the concentration of drug at which the binding capacity is half-maximally saturated. The model reduction process also provided us with the relationship between the effective parameters $B_{\text {max,cell }}, K_{\mathrm{M} \text {,cell }}$ and the parameters of the original cellular model (7-11):

$$
\begin{aligned}
B_{\text {max }, \text { cell }}= & \mathrm{SF}_{\text {unit }} \cdot \frac{\mathrm{k}_{\text {synR }}}{\mathrm{k}_{\text {degRC }}} \\
K_{\mathrm{M}, \text { cell }}= & \underbrace{\frac{k_{\text {degRC }}+k_{\text {offC }}}{k_{\text {degRC }} \cdot k_{\text {onC }}}}_{\text {drug specific }} \\
& \times \underbrace{\left(\frac{k_{\text {degRi }} k_{\text {degR }}}{k_{\text {degRi }}+k_{\text {recyRi }}}+L \cdot \frac{k_{\text {onL }} \cdot k_{\text {degRL }}}{k_{\text {offL }}+k_{\text {degRL }}}\right)}_{\text {drug independent }} .
\end{aligned}
$$

Note that the maximal binding capacity $B_{\max \text { cell }}$ is only a function of the receptor system and independent of any drug 
properties, while the Michaelis-Menten constant $K_{\mathrm{M} \text {,cell }}$ depends non-linearly on both, receptor parameters as well as drug parameters. Due to the above relationship (14-15), we are able to explicitly compute the parameters $B_{\max \text { cell }}$ and $K_{\mathrm{M} \text {,cell }}$ based on the in vitro determined parameters $k_{\text {synR }}, k_{\text {degR }}, k_{\text {degRC }}, k_{\text {recyRi }}, k_{\text {onL }}, k_{\text {offL }}, k_{\text {degRL }}$ of the singlecell model, the in vivo determined EGF concentration $L$, and the drug-specific parameters $k_{\text {onC }}, k_{\text {offC }}, k_{\text {degRC}}$.

We then determined the number of relevant cells $N$ as the factor that scales the single-cell binding capacity $B_{\text {max,cell }}$ to the whole-body binding capacity $B_{\text {max,PK}}$ :

$B_{\text {max }, \mathrm{PK}}=N_{\text {cell }} \cdot B_{\text {max }, \text { cell }} \cdot$

Inserting the relationship (14) of $B_{\max , \text { cell, we obtained }}$

$N_{\text {cell }}=\frac{k_{\mathrm{degRC}} \cdot B_{\mathrm{max}, \mathrm{PK}}}{k_{\mathrm{synR}} \cdot \mathrm{SF}_{\mathrm{unit}}}$.

Note that all parameter values are known, so we may explicitly determine $N_{\text {cell }}$ from Eq. 17. In addition, we defined the in vitro-in vivo scaling factor $\mathrm{SF}_{\text {iviv }}$ between the concentrations of half-maximal binding capacity by

$K_{\mathrm{M}, \mathrm{PK}}=\mathrm{SF}_{\mathrm{iviv}} \cdot \mathrm{K}_{\mathrm{M} \text {,cell }}$

The scaling factor $\mathrm{SF}_{\text {iviv }}$ accounts for potential differences between conditions in vitro and in vivo.

Next, we present our approach based on a single cell type as a reference cell. We remark that the underlying compartment model including the linear clearance part was taken from the model by Lammerts van Bueren et al. as stated in Eqs. 1-3. In the second part of this article we then extend the cell-level PK/PD model to include multiple reference cell type (tumor and normal cells). Along the same lines, entire distributions of cell types could be integrated e.g., to account for spatial inhomogeneities as they are expected in solid tumors.

\section{Cell-level pharmacokinetic/pharmacodynamic model}

The presented approach allowed a systematic integration of the single-cell level into the compartment model. Based on the number of relevant cells $N_{\text {cell }}$, we replaced the apparent drug-receptor interaction term in Eqs. 2, 3 by the the drug-ligand-receptor model. The terms accounting for the drug-receptor interaction were scaled to the wholebody level by $N_{\text {cell }}$. The resulting single-cell PK/PD model is given by:

$V_{\mathrm{pla}} \frac{\mathrm{d} C_{\mathrm{pla}}}{\mathrm{d} t}=-q_{\mathrm{pi}} C_{\mathrm{pla}}+q_{\mathrm{ip}} C_{\mathrm{int}}-\mathrm{CL}_{\mathrm{lin}} \cdot C_{\mathrm{pla}}$

$$
\begin{aligned}
V_{\mathrm{int}} \frac{\mathrm{d} C_{\mathrm{int}}}{\mathrm{d} t}= & +q_{\mathrm{pi}} C_{\mathrm{pla}}-q_{\mathrm{ip}} C_{\mathrm{int}} \\
& +N_{\text {cell }} \cdot \underbrace{\left(k_{\mathrm{offC}} \cdot \mathrm{SF}_{\mathrm{unit}} \cdot R C-k_{\mathrm{onC}} \cdot \mathrm{SF}_{\text {unit }} \cdot R \cdot C_{\mathrm{int}}\right)}_{\text {whole-body single }- \text { cell level interaction }}
\end{aligned}
$$

$\frac{\mathrm{d} R}{\mathrm{~d} t}=k_{\mathrm{synR}}-k_{\mathrm{onL}} R \cdot L-k_{\mathrm{onC}} R \cdot C_{\mathrm{int}}+k_{\mathrm{offL}} R L$

$$
+k_{\mathrm{offC}} R C-k_{\mathrm{degR}} \cdot R+k_{\mathrm{recyRi}} \cdot R_{\mathrm{i}}
$$

$\frac{\mathrm{d} R_{\mathrm{i}}}{\mathrm{d} t}=k_{\mathrm{degR}} \cdot R-k_{\mathrm{recyRi}} \cdot R_{\mathrm{i}}-k_{\mathrm{degRi}} \cdot R_{\mathrm{i}}$

$\frac{\mathrm{d} R L}{\mathrm{~d} t}=k_{\mathrm{onL}} \cdot L \cdot R-k_{\mathrm{offL}} R L-k_{\mathrm{degRL}} R L$

$\frac{\mathrm{d} R C}{\mathrm{~d} t}=k_{\mathrm{onC}} \cdot C_{\mathrm{int}} \cdot R-k_{\mathrm{offC}} R C-k_{\mathrm{degRC}} \cdot R C$

that describe the rate of change of the therapeutic antibody in plasma $C_{\text {pla }}$ and in the interstitial space $C_{\text {int }}$, the free receptor $R$, the internalized receptor $R_{\mathrm{i}}$, the drug-receptor complex $R C$, the EGF ligand in the interstitial space $L$ and the ligand-receptor complex $R L$. Rather than just re-estimating parameters of the single-cell PK/PD model, the above approach established a mechanistic link between the kinetic model of the receptor system at the single-cell level and the apparent term in the whole-body compartment model. As part of our approach, we provided a systematic way of determining an apparent drug-receptor model from a detailed cell-level description. This has been further elaborated in [28], where we have also shown that the reduced model (12-13) is a more appropriate description of the apparent drug-receptor interaction in the compartment model (1-3), since it eliminates the use of the artificial rate constant $k_{\mathrm{b}}$.

Measures of receptor saturation, residual activity and inhibition

Receptor saturation by the drug, defined as

receptor saturation $=\frac{R C}{R+R L+R C}$,

is often taken as a measure of the inhibitory potential of a drug. We compared receptor saturation with the residual receptor activation

residual receptor activity $=\frac{R L}{R L^{*}}$,

defined relative to the pre-treatment level $R L^{*}$ of activated receptors.

We analyzed the impact of mAb treatment of target cells with respect to three quantitative measures. The measures 
Fig. 2 Schematic illustration of the cell-level PK/PD model for analyzing the inhibitory effect on receptor activation of antiEGFR antibodies. a Cell-level receptor model of receptor activation and inhibition. The cellular model describes the transient inhibitory effect of a therapeutic antibody by competitively binding the targeted receptor and thereby decreasing the active ligandreceptor complexes. b Celllevel PK/PD model used to study the trajectory of the drug concentration and the impact of biophysical properties of antiEGFR antibodies. $\mathbf{c}$ Three different transient measures of the reduction in the number of active receptors: the integral, the peak, and the duration of inhibition. d Extended cell-level PK/PD model including tumor cells with elevated EGFR levels due to alteration of receptor dynamics used to compare the inhibitory effect of therapeutic antibodies on tumor cells and normal cells to optimize tumor specificity

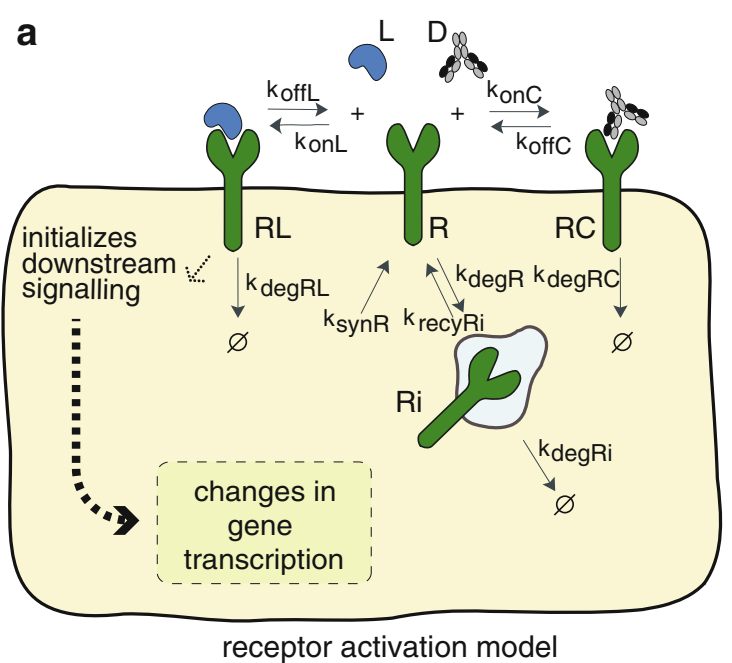

b

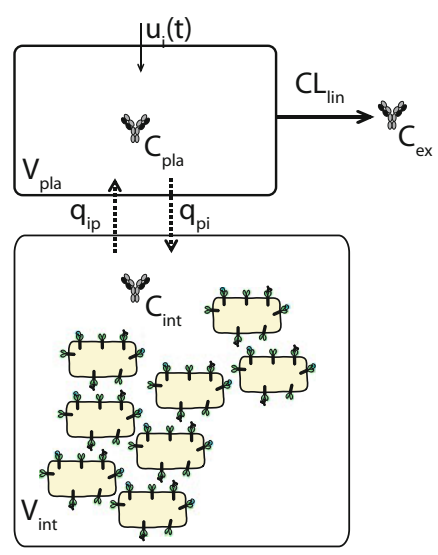

C

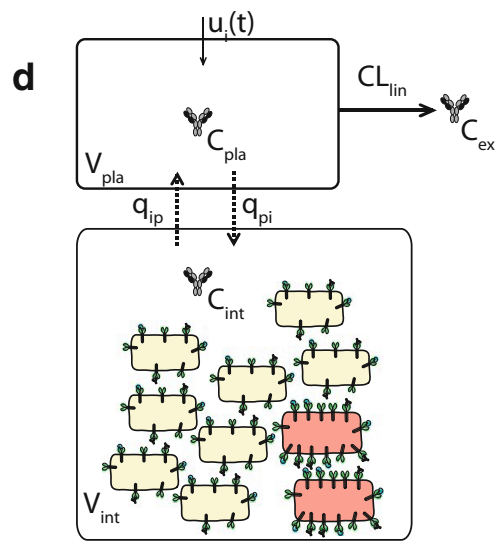

of transient response are illustrated in Fig. $2 \mathrm{c}$ and are defined as follows:

- The integral of inhibition: Cumulative EGF receptors that are not activated as a consequence of drug treatment. More formally, the integral of inhibition is defined as area under the curve of the active receptors with respect to their steady state pre-treatment level $R L^{*}$, i.e.,

$E=\int_{0}^{\infty}\left(R L^{*}-R L(t)\right) d t$.

- The peak inhibition: Maximal reduction in activated EGFR as a fraction of pre-treatment level $R L^{*}$ :

peak $=\frac{R L^{*}-\min \{R L\}}{R L^{*}}$.

- The duration of inhibition: Time needed to recover to $75 \%$ of the pre-drug level of activated receptors.

The chosen measures of inhibition resemble important characteristics of drug effect. For small molecule drugs, the integral of inhibition (exposure) is often related to the drug effect, while the peak inhibition or the duration of inhibition (measuring some threshold characteristics) are often related to the side effects.
For different cell types, e.g., normal and tumor cells, we defined the antibody specificity $S$ as the ratio of the inhibitory effect on tumor to normal cells. For the three measures of transient response, this amounted to

$S_{E}=\frac{E_{\text {tumor }}}{E_{\text {normal }}}, S_{p}=\frac{\text { peak }_{\text {tumor }}}{\text { peak }_{\text {normal }}}, S_{d}=\frac{\text { dur }_{\text {tumor }}}{\text { dur }_{\text {normal }}}$,

where 'dur' denotes duration.

Cell-level pharmacokinetic/pharmacodynamic model with normal and tumor cells

To illustrate our approach and its potential application to different cell types, we integrate tumor cells into the celllevel PK/PD model. For this purpose, we consider only tumor cells that are exposed to the same drug concentration time profile as normal cells. This assumption is expected to hold for tumor cells close to the vasculature, but it is most likely inadequate for cells in solid tumors (in which case model the should be extended to account for a tumor distribution model). To compare the response of normal and tumor cells to anti-EGFR antibodies, we extended our model by integrating a kinetic cellular model representing tumor cells with elevated EGFR levels (Fig. 2d). The rate of change of all molecular species is given as follows, 
where the subscripts $\mathrm{N}$ and $\mathrm{T}$ refer to normal and tumor cells:

$$
\begin{aligned}
V_{\mathrm{pla}} \frac{\mathrm{d} C_{\mathrm{pla}}}{\mathrm{d} t} & =-q_{\mathrm{pi}} C_{\mathrm{pla}}+q_{\mathrm{ip}} C_{\mathrm{int}}-C L_{\mathrm{lin}} \cdot C_{\mathrm{pla}} \\
V_{\mathrm{int}} \frac{\mathrm{d} C_{\mathrm{int}}}{\mathrm{d} t}= & +q_{\mathrm{pi}} C_{\mathrm{pla}}-q_{\mathrm{ip}} C_{\mathrm{int}} \\
& +N_{\mathrm{N}} \cdot \underbrace{\left(k_{\mathrm{offC}} \cdot \mathrm{SF}_{\mathrm{unit}} \cdot R C_{\mathrm{N}}-k_{\mathrm{onC}} \cdot \mathrm{SF}_{\mathrm{unit}} \cdot R_{\mathrm{N}} \cdot C_{\mathrm{int}}\right)}_{\text {normal cells }}
\end{aligned}
$$

$$
+N_{\mathrm{T}} \cdot \underbrace{\left(k_{\mathrm{offC}} \cdot \mathrm{SF}_{\text {unit }} \cdot R C_{\mathrm{T}}-k_{\mathrm{onC}} \cdot \mathrm{SF}_{\text {unit }} \cdot R_{\mathrm{T}} \cdot C_{\mathrm{int}}\right)}_{\text {tumor cells }}
$$

$$
\begin{aligned}
\frac{\mathrm{d} R_{\mathrm{N}}}{\mathrm{d} t}= & k_{\mathrm{synR}, \mathrm{N}}-k_{\mathrm{onL}} R_{\mathrm{N}} L-k_{\mathrm{onC}} R_{\mathrm{N}} C_{\mathrm{int}}+k_{\mathrm{offL}} R L_{\mathrm{N}} \\
& +k_{\mathrm{offC}} R C_{\mathrm{N}}-k_{\mathrm{degR}, \mathrm{N}} R_{\mathrm{N}}+k_{\mathrm{recyRi}} R_{\mathrm{iN}} \\
\frac{\mathrm{d} R_{\mathrm{i}, \mathrm{N}}}{\mathrm{d} t}= & k_{\mathrm{degR}, \mathrm{N}} \cdot R_{\mathrm{N}}-k_{\mathrm{recyRi}} \cdot R_{\mathrm{i}, \mathrm{N}}-k_{\mathrm{degRi}} \cdot R_{\mathrm{i}, \mathrm{N}} \\
\frac{\mathrm{d} R_{\mathrm{LN}}}{\mathrm{d} t}= & k_{\mathrm{onL}} L \cdot R_{\mathrm{N}}-k_{\mathrm{offL}} R L_{\mathrm{N}}-k_{\mathrm{degRL}, \mathrm{N}} R L_{\mathrm{N}} \\
\frac{\mathrm{d} R C_{\mathrm{N}}}{\mathrm{dt}}= & k_{\mathrm{onC}} C_{\mathrm{int}} \cdot R_{\mathrm{N}}-k_{\mathrm{offC}} R C_{\mathrm{N}}-k_{\mathrm{degRC}} \cdot R C_{\mathrm{N}}, \\
\frac{\mathrm{d} R_{\mathrm{T}}}{\mathrm{d} t}= & k_{\mathrm{synR}, \mathrm{T}}-k_{\mathrm{onL}} R_{\mathrm{T}} L-k_{\mathrm{onC}} R_{\mathrm{T}} C_{\mathrm{int}}+k_{\mathrm{offL}} R L_{\mathrm{T}} \\
& +k_{\mathrm{offC}} R C_{\mathrm{T}}-k_{\mathrm{degR}, \mathrm{T}} R_{\mathrm{T}}+k_{\mathrm{recyRi}} R_{\mathrm{i}, \mathrm{T}} \\
\frac{\mathrm{d} R_{\mathrm{i}, \mathrm{T}}}{\mathrm{d} t}= & k_{\mathrm{degR}, \mathrm{T}} \cdot R_{\mathrm{T}}-k_{\mathrm{recyRi}} \cdot R_{\mathrm{i}, \mathrm{T}}-k_{\mathrm{degRi}} \cdot R_{\mathrm{i}, \mathrm{T}} \\
\frac{\mathrm{d} R L_{\mathrm{T}}}{\mathrm{d} t}= & k_{\mathrm{onL}} L \cdot R_{\mathrm{T}}-k_{\mathrm{offL}} R L_{\mathrm{T}}-k_{\mathrm{degRL}, \mathrm{T}} R L_{\mathrm{T}} \\
\frac{\mathrm{d} R C_{\mathrm{T}}}{\mathrm{d} t}= & k_{\mathrm{onC}} C_{\mathrm{int}} \cdot R_{\mathrm{T}}-k_{\mathrm{offC}} R C_{\mathrm{T}}-k_{\mathrm{degRC}} \cdot R C_{\mathrm{T}} .
\end{aligned}
$$

The parameters for tumor cells are identical to those of normal cells, except for those specified below. Elevated EGFR levels may be caused by a variety of alterations at the target cell level. In the sequel, we analyzed the dynamics response of two tumor cell types that have comparable elevated EGFR levels prior to drug treatment: (i) cells with increased receptor synthesis rate $\left(k_{\mathrm{SynR}, \mathrm{N}}\right.$ Vs. $\left.k_{\mathrm{synR}, \mathrm{T}}\right)$; and (ii) cells with decreased receptor internalization $\left(k_{\mathrm{degR}, \mathrm{N}}, k_{\mathrm{de}-}\right.$ gRL,N Vs. $\left.k_{\mathrm{degR}, \mathrm{T}}, k_{\mathrm{degRL}, \mathrm{T}}\right)$. Both tumor cell types have been observed experimentally [31-34]. We set the number of tumor cells to $1 \%$ of the normal cells so that it had little impact on the pharmacokinetics (comparable to the situation in Bleeker et al. [25] in mice). The tumor cell model represents those tumor cells exposed to drug concentrations equivalent to the exposure of cells with normal EGFR levels.

\section{Methods}

For the single-cell PK/PD model with normal cells only, the system is assumed to be in steady state prior to any drug administration, resulting in a number of free receptors $R^{*}$, active receptors $R L^{*}$, and zero drug-receptor complexes $R C^{*}=0$. Similarly, for the model with normal and tumor cells, the steady state levels are defined by $R_{\mathrm{N}}^{*}, R L_{\mathrm{N}}^{*}$, and $R C_{\mathrm{N}}^{*}=0, R_{\mathrm{T}}^{*}, R L_{\mathrm{T}}^{*}$, and $R C_{\mathrm{T}}^{*}=0$.

The response to a bolus dose $C_{0}$ is obtained by numerical integration of the corresponding system of ODEs with the following initial conditions

$$
\begin{array}{lll}
R_{\mathrm{N}}(0)=R_{\mathrm{N}}^{*} & R_{\mathrm{T}}(0)=R_{\mathrm{T}}^{*} & C_{\mathrm{pla}}=C_{0} \\
R L_{\mathrm{N}}(0)=R L_{\mathrm{N}}^{*} & R L_{\mathrm{T}}(0)=R L_{\mathrm{T}}^{*} & C_{\text {int }}=0 \\
R C_{\mathrm{N}}(0)=0 & R C_{\mathrm{T}}(0)=0 . &
\end{array}
$$

For numerical simulations, we used the parameter values given in Table 2. The model was build and simulated using MATLAB (R2011b).

\section{Results}

Predicting the inhibitory effect of the anti-EGFR therapeutic antibody zalutumumab in cynomolgus monkeys

We determined a single-cell PK/PD model for the antiEGFR therapeutic antibody zalutumumab in cynomolgus monkeys. The model based on in vivo data for zalutumumab in cynomolgus monkeys [6], in vitro data of human fibroblast cells [29, 20] and determined drugreceptor affinities [35]. Importantly, our approach does not involve any fitting of parameters; all parameter values were either inherited from the original compartment model, determined in vitro, or explicitly calculated.

\section{Evaluation against in vivo data}

To evaluate the single cell PK/PD model, we compared our model predictions with the experimental data of zalutumumab in cynomolgus monkeys. Based on the described integration process, we determined the number of relevant cells as $N_{\text {cell }}=5.2 \cdot 10^{9}$ and the in vitro-in vivo scaling factor as $\mathrm{SF}_{\text {iviv }}=2.1$. The small scaling factor $\mathrm{SF}_{\text {iviv }}$ was considered as supporting evidence for the chosen single-cell model. Furthermore, the predicted timecourses of the drug concentrations showed very good agreement for the high, medium and low dose of $40 \mathrm{mg} / \mathrm{kg}$, $20 \mathrm{mg} / \mathrm{kg}$ and $2 \mathrm{mg} / \mathrm{kg}$ dose (Fig. 3a). 
Table 2 Parameter values for the EGF receptor system

\begin{tabular}{lllll}
\hline Name & Definition & Value & Unit & References \\
\hline $\mathrm{k}_{\text {onL }}$ & Ligand-receptor binding & $7.2 \cdot 10^{-2}$ & $1 /(\mathrm{nM} \cdot \mathrm{min})$ & {$[20]$} \\
$\mathrm{k}_{\text {offL }}$ & Ligand-receptor unbinding & 0.34 & $1 / \mathrm{min}$ & {$[20]$} \\
$\mathrm{k}_{\text {degR }}$ & Free receptor internalization & 0.03 & $1 / \mathrm{min}$ & {$[20]$} \\
$\mathrm{k}_{\text {degRL }}$ & Ligand-receptor complex internalization & 0.03 & $1 / \mathrm{min}$ & {$[20]$} \\
$\mathrm{k}_{\mathrm{R}, \mathrm{N}}$ & Receptor expression rate in normal cells & 130 & Receptors/min per cell \\
$\mathrm{k}_{\text {recyRi }}$ & Free receptor recycling & $5.8 \cdot 10^{-2}$ & $1 / \mathrm{min}$ & {$[20]$} \\
$\mathrm{k}_{\mathrm{degRi}}$ & Free receptor degradation & $2.2 \cdot 10^{-3}$ & $1 / \mathrm{min}$ & {$[20]$} \\
$\mathrm{k}_{\text {onC }}$ & Drug-receptor binding & $k_{\text {onL }}$ & $1 /(\mathrm{nM} \cdot \mathrm{min})$ \\
$\mathrm{k}_{\mathrm{degRC}}$ & Drug-receptor complex internalization & 0.005 & $1 / \mathrm{h}$ & {$[20]$} \\
$\mathrm{MW}_{\mathrm{mAbs}}$ & Molecular weight & 148000 & Dalton $(\mathrm{g} / \mathrm{mol})$
\end{tabular}

For monkeys, $k_{\text {recyRi }}$ and $k_{\mathrm{degR}}$ were multiplied by a factor of 4 and $1 / 4$, respectively to account for species differences

At the same time, the cell-level pharmacokinetic model was used to predict the dynamics of the receptor system upon drug administration (Fig. 3b). In agreement with experimental findings reported in [6] (Table 3), the model predicted that a saturation in monkey tissue which expresses normal receptor levels was established at doses between 2 and $20 \mathrm{mg} / \mathrm{kg}$ (Fig. 3b, inset). We considered the agreement between our model and the data available in [6] as validation to proceed confidently in our study. The available data considers 2 and $20 \mathrm{mg} / \mathrm{kg}$ doses, and therefore in the sequel we will restrict our analysis to these doses only.

Predicting residual EGFR activity per cell

The cell-level PK/PD model then was used to predict the number of activated receptors over the duration of the treatment, which is difficult to examine in vivo. Our model predicted that the low dose $(2 \mathrm{mg} / \mathrm{kg})$ of antibody reduces the number of active receptors by about $35 \%$. The steep initial decrease in receptor activation is followed by a recovery period secondary to a slow reduction of drug concentration (Fig. 3b). On the other hand, the higher dose $(20 \mathrm{mg} / \mathrm{kg}$ ) almost completely inhibited receptor activation for a period of about 20 days. The start of the recovery period coincided with the transition from saturated to linear pharmacokinetics between days 20 and 25. The model therefore suggests that changes in pharmacokinetics mays act as a biomarker for changes in the inhibitory response.

Comparing receptor saturation (25) with residual receptor activity (26), we found that both characteristics only corresponded initially, while at later points in time the receptor saturation underestimated the inhibitory effect of the antibody (e.g. compare with the $20 \mathrm{mg} / \mathrm{kg}$ dose after 50 days). This highlights the importance of adopting an integrated kinetic model to translate the binding of the drug into its actual inhibitory effect on receptor activation.

Impact of drug characteristics on receptor inhibition

One advantage of the cell-level PK/PD model is its ability to predict the impact of drug properties such as the dose, drug-receptor affinity, and drug induced receptor internalization on the inhibitory response under in vivo conditions. We assumed that the target independent PK distribution parameters $V_{\text {pla }}, V_{\text {int }}, q_{\text {pi }}$ and $q_{\text {ip }}$ do not change when changing properties of the $\mathrm{F}(\mathrm{ab})$ region. Since all the analyzed antibodies are either of IgG1 or IgG2 isotype, their target-independent clearance was also assumed to be identical [36].

\section{Affinity and dose}

We studied the inhibitory effect for a range of affinities, including those of anti-EGFR mAbs on the market or in clinical development: zalutumumab, panitumumab, cetuximab, IMC-11F8, and nimotuzumab (see Table 4). All these antibodies act antagonistically [37]. Different affinities $K_{\mathrm{D}}$ were realized by changing the dissociation rate constant $k_{\text {offC }}$, while the association rate constant $k_{\text {onC }}$ was assumed to be diffusion-limited and therefore left unchanged. Our analysis focused on the F(ab)-mediated direct inhibitory effect, i.e., on the reduction in the number of activated receptors at the cell membrane.

The percentage of active receptors over time is shown in Fig. 4a. Despite 20-fold differences in target affinities (see Table 4), the transient inhibition pattern were surprisingly similar. As can be seen in Fig. 4b-d, this phenomenon is a consequence of an effect plateau in the inhibitory responses. For high affinity drugs located in the plateau range, an increased affinity does not translate into a noticeable 


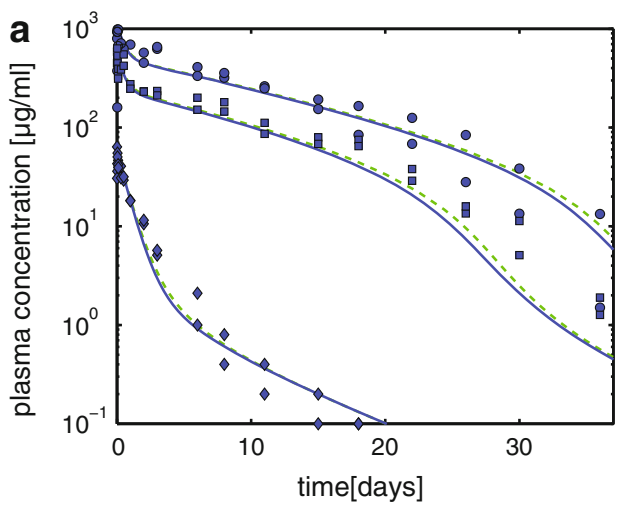

Fig. 3 Pharmacokinetics of zalutumumab in cynomolgus monkeys and prediction of the inhibitory effect on a cellular level using themodel depicted in Fig. 2b. a Predicted plasma concentration of zalutumumab by the cell-level PK/PD model (solid line) and the compartment PK model of Lammerts van Bueren et al. [6] (dashed line) for a high, medium and low dose of 40,20 and $2 \mathrm{mg} / \mathrm{kg}$. The experimental data for zalutumumab in cynomolgus monkeys are

Table 3 Pharmacodynamics of zalutumumab in cynomolgus monkeys for different doses as reported in Lammerts van Bueren et al. [6] and predicted by the single-cell PK/PD model (see Fig. 3)

\begin{tabular}{lll}
\hline Dose $(\mathrm{mg})$ & In vivo experiment & In silico prediction \\
\hline 2 & Not fully saturated & Max. $60 \%$ saturated \\
20 & Fully saturated & $100 \%$ saturated \\
40 & Fully saturated & $100 \%$ saturated \\
\hline
\end{tabular}

Table 4 Affinities and isotypes of the different therapeutic antibodies against the EGFR. Values taken from Peipp et al. [35]

\begin{tabular}{lll}
\hline Antibody & Affinity/avidity $(\mathrm{M})$ & Isotype \\
\hline Panitumumab & $5 \cdot 10^{-11}$ & $\mathrm{IgG} 2$ \\
Cetuximab & $4 \cdot 10^{-10}$ & $\mathrm{IgG} 1$ \\
IMC-11F8 & $3 \cdot 10^{-10}$ & $\mathrm{IgG} 1$ \\
Nimotuzumab & $1 \cdot 10^{-9}$ & $\mathrm{IgG} 1$ \\
Zalutumumab & $7 \cdot 10^{-9}$ & $\mathrm{IgG} 1$ \\
\hline
\end{tabular}

The $K_{\mathrm{D}}$ (affinity) values were subsequently scaled with $\mathrm{SF}_{\text {iviv }}$, i.e., $K_{\mathrm{D}}$ (invivo) $=\mathrm{SF}_{\text {iviv }} \cdot \mathrm{K}_{\mathrm{D}}$ (invitro) to account for differences between conditions in vitro and in vivo. While potentially the scaling factors for $K_{M}$ (see Eq. 18) and $K_{\mathrm{D}}$ could be different, we used the same scaling factor $\mathrm{SF}_{i}$ viv due to lack of further information and based on the principle of parsimony. See also footnote to Table 1 of [35], where affinity values are reported

stronger inhibition. Mathematical analysis of the model (Appendix) for the integral effect suggests that this is a structural feature of the system that does not depend on specific parameter values. Shankaran et al. [19] identified the "consumption parameter", i.e, the ratio of the dissociation and downregulation rate constants $\left(k_{\mathrm{degRC}} / k_{\mathrm{offC}}\right)$, as a key parameter to characterize cell surface receptor

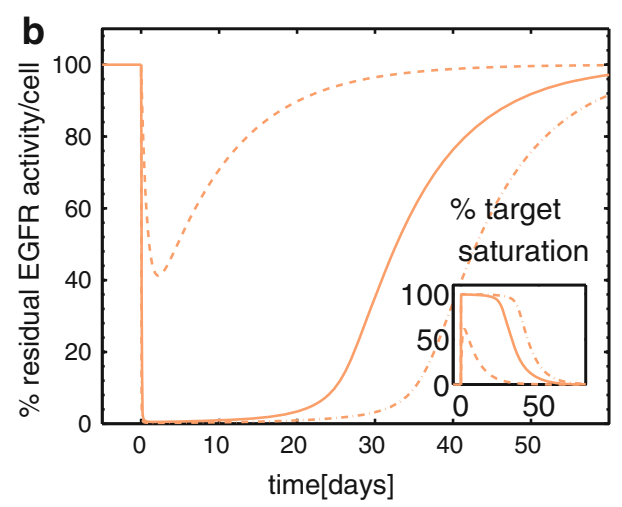

marked with circles (40 mg/kg), squares (20 mg/kg) and diamonds (2 $\mathrm{mg} / \mathrm{kg}$ ). Experimental data courtesy of Wim Bleeker, Genmab, Utrecht, The Netherlands. b Predictions of the residual EGFR activation per cell based on the cell-level pharmacokinetic model (Fig. 2b) for the high dose (dashed dotted line), the medium dose (solid line) and the low dose (dashed line). The inset depicts the corresponding receptor saturation according to Eq. 25

systems. It quantifies the likelihood that a drug, upon binding the receptor, is internalized rather than dissociated. We found that this is also an important parameter for antagonistic mAbs, since those with a high consumption parameter are located on the effect plateau such that their $\mathrm{F}(\mathrm{ab})$-mediated direct inhibitory effect could not be further increased. When decreasing the affinity of the $\mathrm{mAb}$, the clearance effect of binding and internalization became less important than the target independent clearance. As a consequence we found that the drug effect, which is related to receptor binding, decreases for lower affinity.

\section{Downregulation}

Receptor downregulation denotes the drug-induced process of the reducing the number of free receptor at the membrane that is available for binding to the natural ligand. Enforcing receptor downregulation by therapeutic antibodies is argued to be an important part of the drug effect [17]. In Fig. 4b-d, we predicted the inhibitory effect of antibodies with a 5-fold and 10-fold increased internalization rate constant (relative to the rate constant of zalutumumab) for different affinities and low and high doses. We found that for high-affinity antibodies, receptor downregulation only contributes to a negligible extent to the $\mathrm{F}(\mathrm{ab})$-mediated direct inhibitory effect. For medium affinity antibodies, however, an increased downregulation rate constant could increase the direct inhibitory effect to some extent.

\section{Tumor cell specificity}

Upregulation of EGFR expression and aberrant activation of EGFR has been shown in many human epithelial 
Fig. $4 \mathrm{~F}(\mathrm{ab})$-mediated inhibitory effect of different antibodies using the cell-level PK/PD model shown in Fig. 2b. a Predicted transient inhibitory effects of five anti-EGFR antibodies on the market or in clinical development with different affinities (see Table 3) for a $20 \mathrm{mg} / \mathrm{kg}$ dose (solid line) and a $2 \mathrm{mg} / \mathrm{kg}$ dose (dashed line). The different mAbs show a similar transient inhibitory effect despite their affinities vary 20 -fold. b-d Inhibitory effect resulting from different affinities $(\mathrm{KD}=1 /$ affinity $=$ $\mathrm{koffC} / \mathrm{konC}$ ) and downregulation rates $(\mathrm{kdegRC})$ The $F(a b)$-mediated effect is quantified by three different measures: $\mathbf{b}$ the integral of inhibition, $\mathbf{c}$ the peak inhibition, and $\mathbf{d}$ the duration of inhibition, for the $20 \mathrm{mg} / \mathrm{kg}$ dose (solid line) and $2 \mathrm{mg} / \mathrm{kg}$ dose (dashed line). The shaded area indicates the affinity range of the five considered antibodies a
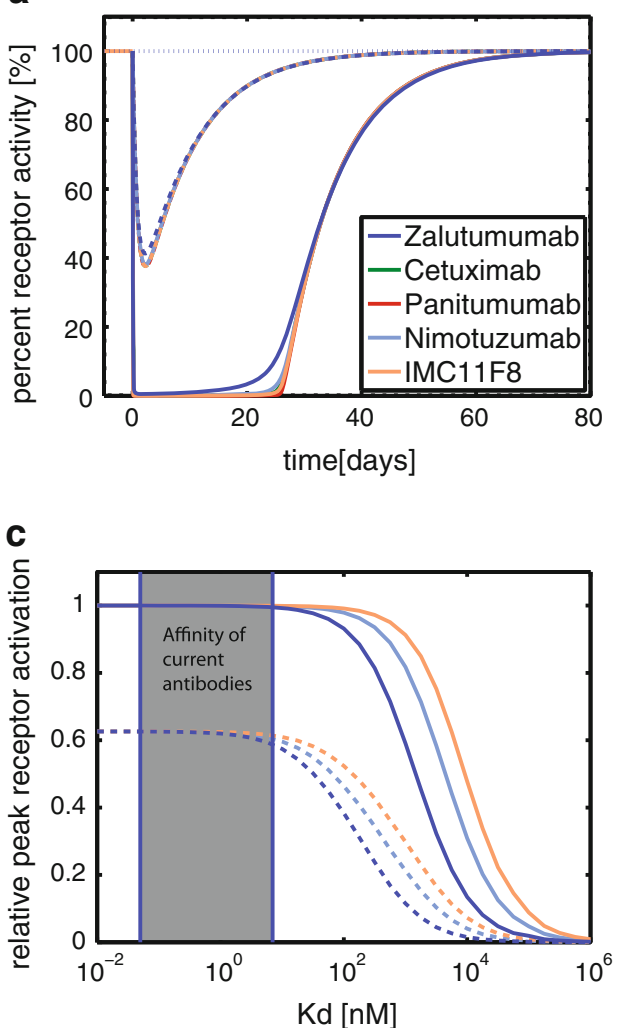

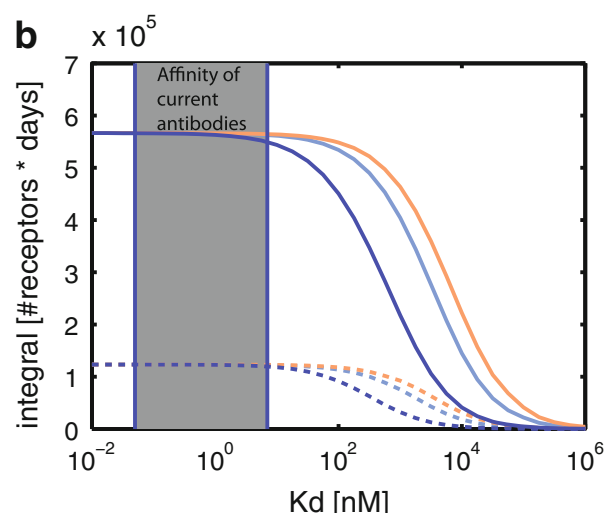

d

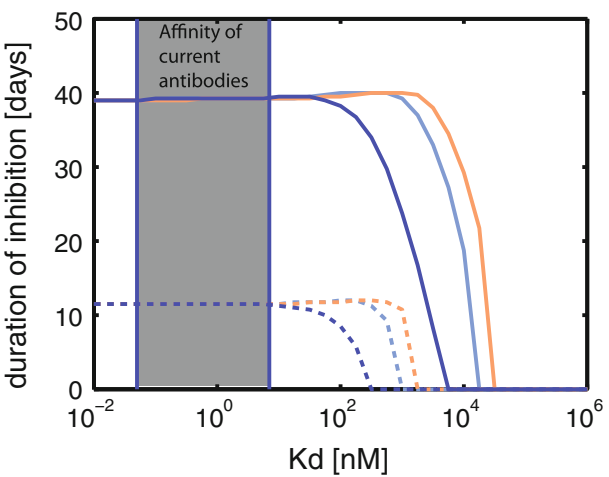

cancers, including those of the colon, lung, kidney, head and neck, breast, prostate, brain and ovary [38-43]. The extent of overexpression also correlates with a poorer clinical outcome [44, 45].

The cellular model for the tumor cells with increased receptor synthesis was chosen to resemble the characteristics of A431 cells, a human squamous carcinoma cell line with high EGFR levels [31- 33]. The overexpression in A431 cell is due to amplification of the EGFR gene [46] and correlates with increased EGF receptor mRNA levels [32]. A431 cells express about 10 times more EGFR at the cell surface than normal cells [31]. The cellular model for the tumor cells with decreased receptor internalization was chosen to resemble the characteristics reported in [34]. Reddy et al. [34] report about an alteration of EFGR where a truncated cytoplasmic domain exhibits a decreased ligand-induced internalization rate constant. Figure 5a illustrates the predicted inhibitory effect in tumor and normal cells in cynomolgus monkeys.

Figure $5 \mathrm{~b}$ compares the predicted transient inhibition for both alterations, increased synthesis rate and reduced internalization. For both alterations, the inhibitory ef fect is strong er for tumor cells than for cells with nor mal EGFR levels. Although both cell alterations resulted in similar steady-state activation levels, their responses to mAbs are remarkably different with cells with decreased receptor internalization showing a higher integral and duration of inhibition compared to cells with an increased synthesis of the receptor.

\section{Discussion}

The objective of this article was to develop a systematic approach to integrate the cellular-level into compartment models of drug PK, and to apply the approach to analyze the $\mathrm{F}(\mathrm{ab})$-mediated inhibitory effect of therapeutic antibodies in cancer therapy.

Several mAbs on the market have a high receptor affinity in the sub-nM range, but the traditional design criterion that "the best binder makes the best drug" has been challenged [47-49]. Using our combined model we evaluated the effect of different affinities of antibodies targeting the EGFR. In cynomolgus monkeys, our celllevel PK/PD model predicts almost identical F(ab)-mediated direct inhibitory effects for a range of antigen-binding affinities. Since current anti-EGFR antibodies are located on the observed effect plateau, this relativizes the affinity amongst the properties that could be further tuned to optimize antibody efficacy.

A high affinity is thought to allow panitumumab to compete more effectively with EGF in binding to EGFR and to saturate EGFR in vivo at lower doses relative to 


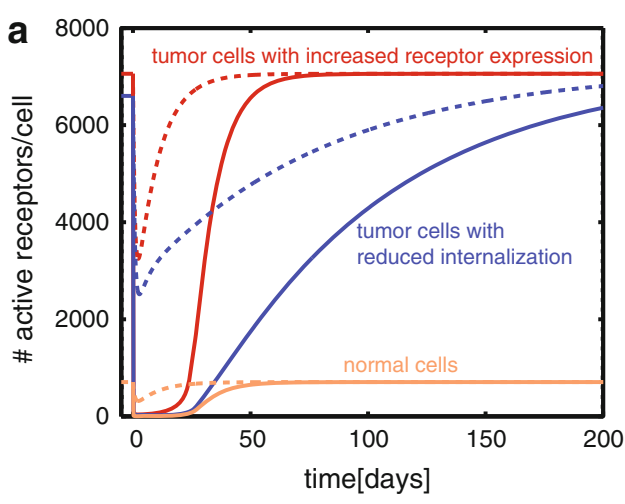

Fig. 5 The mechanism underlying increased receptor levels influences tumor specificity of mAbs. a Predicted transient inhibition based on the extended cell-level pharmacokinetic model shown in Fig. $2 \mathrm{~d}$ for normal cells, tumor cells with a 10-fold increased receptor expression, and tumor cells with a 10-fold decreased internalization of the free and bound receptor. Profiles are shown for the $20 \mathrm{mg} / \mathrm{kg}$ (solid line) and $2 \mathrm{mg} / \mathrm{kg}$ (dashed line) dose. Both scenarios show

mAbs with lower affinity [16]. This is not supported by our analysis, and instead our findings predict that the $F(a b)$ mediated effect of panitumumab and cetuximab are comparable. This prediction of the model is in agreement with experimental results by Messersmith and Hidalgo [50]. We further investigated if this result is due to the specific values of the parameters we used to simulate the model by calculating an analytically solution of the integral of the effect. The analytical solution shows that the existence of an effect plateau is a generic feature of this drug-target system and does not depend on specific parameter values. Therefore this result suggest that such an effect plateau might exist for other receptor systems with receptor trafficking.

Crombet et al. [48] argued that the low degree of adverse effects observed for Nimotuzumab in the clinics is due to its intermediate affinity compared to other antiEGFR antibodies. Their conclusions are based on a mathematical model that only takes into account receptor binding, but neglects the important process of receptor internalization and target specific degradation. Based on our single-cell PK/PD model for cynomolgus monkeys, we find that an intermediate affinity does not result in optimized tumor effect or specificity. Recently, Talavera et al. [51] suggested an alternative explanation for the low degree of adverse effects observed for Nimotuzumab.

Based on the existence of an effect plateau in the F(ab)mediated direct inhibitory effect, our findings suggest that the clinically observed differences among mAbs are likely to arise from $\mathrm{Fc}$-mediated indirect effects, such as the action of immune effector functions (such as antibody dependent cell mediated cytotoxicity or complement dependent cytotoxicity), rather than the direct antagonistic effect. This is consistent with a study of Bleeker et al. showing that effects in

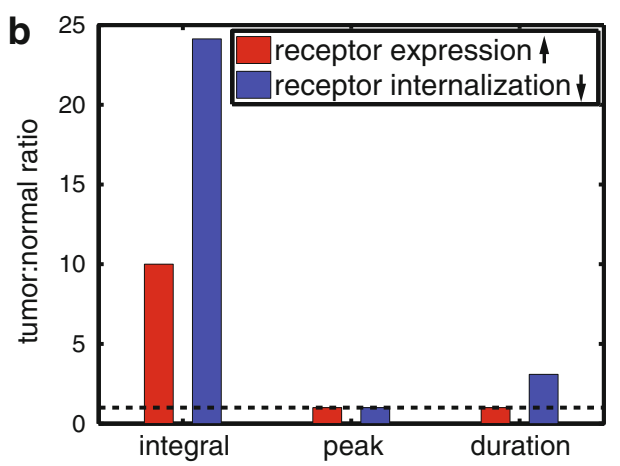

similar steady-state activation levels of the receptor, but their response to drug treatment is substantially different. b Antibody specificity as defined in Eq. 29. Cells with a decreased receptor internalization have a much longer duration of inhibition and therefore a higher integral of inhibition than tumor cells with an increased receptor expression

vivo of zalutumumab and cetuximab differed only by their ability to trigger such indirect effect and not by their direct inhibitory effect [25]. Possible extensions of the model could address the likelihood of triggering such Fc-mediated indirect effects. Since the model predicts the time course of the different receptor species, it may serve as a starting point to estimate the proportion of bound antibody that are presented to the extracellular space and trigger Fc-mediated immune effects.

Alterations of a number of kinetic processes can result in elevated EGFR levels. The combined systems biology/ pharmacokinetic model allows us to study two different tumor cell alterations with elevated EGFR levels resulting from (i) an increased receptor synthesis rate; and (ii) a decreased receptor internalization rate. Both types have been observed experimentally $[46,32,34]$. We found that receptor inhibition over time strongly depends on the underlying molecular alteration that caused the elevated EGFR level.

Our in silico studies show that the inhibitory effects at normal and tumor cells are correlated, and therefore support the hypothesis that the side effects may serve as a marker for the desired effect at the tumor cells. This is in line with experimental observations that the most common side effect of anti-EGFR antibodies are cutaneous toxicities, affecting $45-100 \%$ of patients [52]. Since this skin rash follows from the inhibition of epidermal cells expressing normal levels of the EGFR, using the rash as a marker of drug activity and clinical outcome was proposed [53] and our theoretical study supports this.

The compartment model (1-3) describes the distribution of the drug to the target expressing cells. In this case we described distribution as reversible linear process as previously done when relating plasma concentration to potential pharmacodynamic effect [54]. However, 
processes such as convective movement, lymphatic circulation and filter effects can affect the distribution of antibodies. In these cases, detailed models for antibody distribution e.g. a two pore model (Rippe and Haraldsson, 1994, Physiological reviews) could be integrated into the model. Further, predictions of EGFR inhibition in tumor cells are limited to those malignant cells which are exposed to similar concentrations than normal cells, such as avascular metastases embedded in healthy tissue $[55,56]$. In solid tumors, due to heterogeneous drug distribution, only malignant cells close to capillaries may be exposed to such concentration. Taken together, more detailed models of mAbs distribution, such as physiologically based pharmacokinetics models [57, 58], should be included in cases where distribution of the drug to target cells can not be described by reversible linear processes. The current model also predicts only the decrease in receptor activation rather than the actual biological response of the cell. While Knauer et al. [29] reported a linear dependence between the number of activated EGFR at steady-state and the cellular responses of fibroblasts and epithelial cells, other models describe a more complex relationship between receptor activation and downstream signalling [59].

Established models to study antibody pharmacokinetics include models of TMDD (e.g., Gibiansky et al. [8, 9]). Our cell-level PK/PD model has three important differences compared to TMDD models. First, the model includes the competition of natural ligands with the antibodies for the binding to the receptor. This allows us to study the change of the number of receptor-ligand complexes due to the drug treatment. Second, the model includes more details of the cellular mechanisms. For example, the internal pool of receptors and the recycling to the cell surface are part of the detailed receptor trafficking model, but not of current models of TMDD. We investigated if we could remove this pool together with receptor recycling to make the model more TMDD-like. However, we found this internal pool to be important to describe the initial PK without refitting of the experimentally derived parameters. Our findings support the hypothesis in [6] stating that "possibly, EGFR surface expression can temporarily be replenished with EGFR present in the cell". Third, and most notably, our cell-level PK/PD model integrates in vitro determined parameter values instead of fitting all parameters to the in vivo data. This is useful to avoid over-paramerization of the model, which has be reported to be a critical problem when using the original TMDD model [8].

Combining modelling approaches from pharmacokinetics and systems biology allows us to quantitatively analyse the dynamic interaction between drugs and biological systems [15]. One remaining question concerns the validation of multi-level models. We here used the approach to validate the model prediction using pharmacokinetic data while integrating an in vitro validated cell-level model. Furthermore, we validated the full model using available PK data together with limited PD data. Ideally however, validation should be done using datasets that integrate pharmacokinetic and cell-level data (e.g. receptor phosphorylation) from one source.

We envision that a cell-level PK/PD modeling approach will prove valuable in the emerging field of systems pharmacology. The use of more detailed systems biology models describing downstream signaling processes relevant to human diseases $[13,60,61]$ may eventually allow to translate plasma drug concentration into responses of tumor cells.

Acknowledgments The authors kindly thank Wim Bleeker (Genmab, Utrecht, The Netherlands) for providing the experimental plasma concentration-time data shown in Fig. 3. B. K. and W. H. acknowledge fruitful discussions with Charlotte Kloft (Clinical Pharmacy, Freie Universität Berlin, Germany) and helpful comments on the manuscript from Richard Abadi (University of Manchester/UK), Ken R. Duffy (NUIM/Ireland), and Cormac Taylor (UCD/Ireland). W. H. and B.-F. K. received funding from Merck Serono for their research.

Open Access This article is distributed under the terms of the Creative Commons Attribution License which permits any use, distribution, and reproduction in any medium, provided the original author(s) and the source are credited.

\section{Appendix}

Theoretical analysis of the integral of inhibition

The inhibitory effect can be studied by looking at the response of the model linearized around the steady state activation level. In what follows we derive a formula for the integral of inhibition in the linear system, which provides an estimate for that of the original system.

The steady state of model $(20-40)$ is

$$
\begin{aligned}
& x^{*}=\left[\begin{array}{lllllllll}
C_{\mathrm{int}}^{*} & C_{\mathrm{pla}}^{*} & R_{\mathrm{N}}^{*} & R_{\mathrm{i}}^{*} & R L_{\mathrm{N}}^{*} & R C_{\mathrm{N}}^{*} & R_{\mathrm{T}}^{*} & R_{\mathrm{i}, \mathrm{T}}^{*} & R L_{\mathrm{T}}^{*} \\
R C_{\mathrm{T}}^{*}
\end{array}\right], \\
&
\end{aligned}
$$

and we know that $C_{\mathrm{int}}^{*}=C_{\mathrm{pla}}^{*}=R C_{\mathrm{N}}^{*}=R C_{\mathrm{T}}^{*}=0 . \mathrm{We}$ assume that the steady state is exponentially stable, which for any realistic scenario is trivially satisfied. This guarantees that the integral of the inhibition

$E=\int_{0}^{\infty}\left(R L_{\mathrm{N}}^{*}-R L_{\mathrm{N}}(t)\right) d t$,

is a finite number. The deviations of the model variables with respect to the steady state are 
$\overline{R_{\mathrm{N}}}=R_{\mathrm{N}}^{*}-R_{\mathrm{N}} \quad \overline{R_{\mathrm{T}}}=R_{\mathrm{T}}^{*}-R_{\mathrm{T}} \quad \overline{C_{\text {pla }}}=-C_{\text {pla }}$

$\bar{R}_{\mathrm{i}}=R_{\mathrm{i}}^{*}-R_{\mathrm{i}} \quad R_{\mathrm{i}, \mathrm{T}}=R_{\mathrm{i}, \mathrm{T}}^{*}-R_{\mathrm{i}, \mathrm{Y}} \quad C_{\mathrm{int}}=-C_{\mathrm{int}}$

$R \bar{L}_{\mathrm{N}}=R L_{\mathrm{N}}^{*}-R L_{\mathrm{N}} \quad R \bar{L}_{\mathrm{T}}=R L_{\mathrm{T}}^{*}-R L_{\mathrm{T}}$

$R \bar{C}_{\mathrm{N}}=-R C_{\mathrm{N}} \quad R \bar{C}_{\mathrm{T}}=-R C_{\mathrm{T}}$

We define a state vector as

$\bar{x}=\left[\bar{C}_{\mathrm{pla}} \bar{C}_{\mathrm{int}} \overline{R_{\mathrm{N}}} \bar{R}_{\mathrm{i}} R \bar{L}_{\mathrm{N}} R \bar{C}_{\mathrm{N}} \overline{R_{\mathrm{T}}} \overline{R_{\mathrm{i}, \mathrm{T}}} R \bar{L}_{\mathrm{T}} R \bar{C}_{\mathrm{T}}\right]^{T}$

Linearizing the model around the steady state leads to

$\frac{\mathrm{d} \bar{x}}{\mathrm{~d} t}=\boldsymbol{A} \bar{x}$.

The matrix $\boldsymbol{A} \in \mathbb{R}^{10 \times 10}$ is given in Eq. 53 and corresponds to the Jacobian of the right hand side of (30-40) evaluated at the steady state. Integration of (43) from $t=0$ up to $t=\infty$ gives
Computing the inverse $\boldsymbol{A}^{-1}$ we get

$E=\frac{\alpha R L_{\mathrm{N}}^{*}}{\beta+\gamma \frac{1}{k_{\mathrm{onC}}}\left(\frac{1}{\mathrm{CP}}+1\right)}$,

with the constants:

$$
\begin{aligned}
\alpha & =V_{\mathrm{pla}} R_{\mathrm{N}}^{*} q_{\mathrm{cp}} C \frac{k_{\mathrm{degR}}}{k_{\mathrm{onL}} L}\left(\frac{k_{\mathrm{offL}}+k_{\mathrm{degRL}}}{k_{\mathrm{recyRi}}+k_{\mathrm{degRi}}}\right), \\
\beta & =k_{\mathrm{synR}, \mathrm{N}} \mathrm{SF}_{\mathrm{unit}}\left(\mathrm{q}_{\mathrm{cp}}+\mathrm{CL}_{\mathrm{lin}}\right)\left(\mathrm{N}_{\mathrm{N}} \mathrm{R}_{\mathrm{N}}^{*}+\mathrm{N}_{\mathrm{T}} \mathrm{R}_{\mathrm{T}}^{*}\right) \\
\gamma & =k_{\mathrm{R}, \mathrm{N}} \mathrm{CL}_{\mathrm{lin}} \mathrm{q}_{\mathrm{pc}}
\end{aligned}
$$

The parameter $K_{\mathrm{d}}=1 /$ affinity and the "consumption parameter" defined by in [19] are given by

$$
K_{\mathrm{D}}=\frac{k_{\text {offC }}}{k_{\mathrm{onC}}} \quad \mathrm{CP}=\frac{k_{\mathrm{degRC}}}{k_{\text {offC }}} .
$$

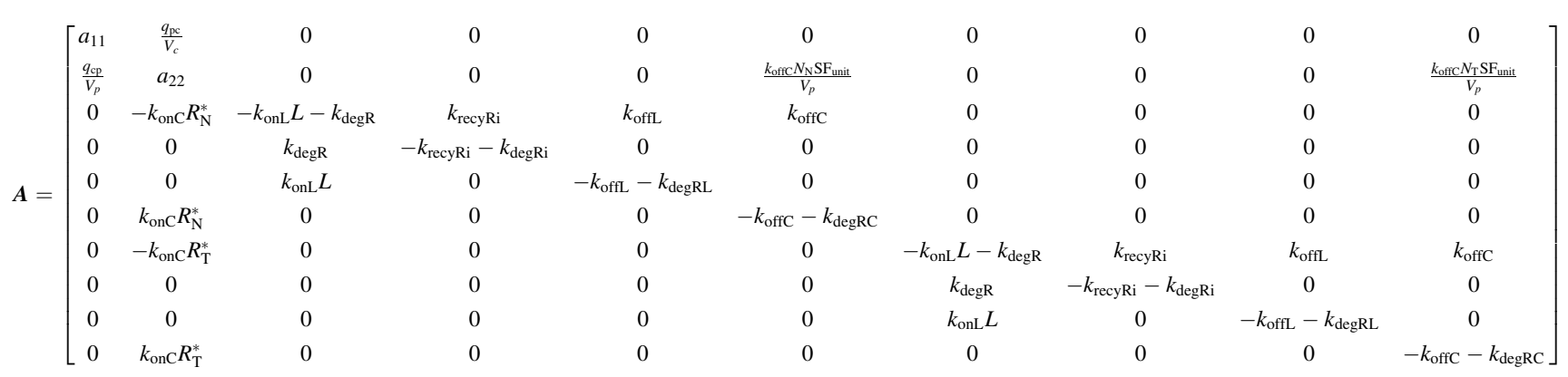

$\bar{x}(\infty)-\bar{x}(0)=\boldsymbol{A} \int_{0}^{\infty} \bar{x}(t) d t$.

For a bolus dose $C$ at $t=0$ the initial condition for (43) is

$\bar{x}(0)=\left[\begin{array}{lllll}-C & 0 & 0 & \ldots & 0\end{array}\right]^{T}$.

The stability of the equilibrium implies that $\bar{x}(\infty)=0$, which upon substitution in (44) yields

$$
\int_{0}^{\infty} \bar{x}(t) d t=-\boldsymbol{A}^{-1} \bar{x}(0) .
$$

From (42) we notice that the integral of inhibition $E$ is the 5 th entry of the vector in (46). Hence

$E=\int_{0}^{\infty} \bar{x}_{5}(t) d t=-\left[\boldsymbol{A}^{-1} \bar{x}(0)\right]_{5}$.
The effect $E$ is a decreasing function of $k_{\text {offC }}$ and shows little variations for the values of $K_{\mathrm{D}}$ for the mAbs in Table 4. All these mAbs are located in a plateau region of the effect $E$. This linear analysis suggests that the effect plateau is a structural feature of the system and does not depend on the parameter values.

$a_{11}=\frac{-1}{V_{c}}\left(q_{\mathrm{cp}}+C L_{\mathrm{linC}}\right)$

$a_{22}=\frac{-1}{V_{p}}\left(k_{\mathrm{onC}} N_{\mathrm{N}} \mathrm{SF}_{\text {unit }} R_{\mathrm{N}}^{*}+k_{\mathrm{onC}} N_{\mathrm{T}} \mathrm{SF}_{\text {unit }} R_{\mathrm{T}}^{*}+q_{\mathrm{pc}}\right)$

\section{References}

1. Meibohm B (2007) The role of pharmacokinetics and pharmacodynamics in the development of biotech drugs. In: Meibohm B (ed) 
Pharmacokinetics and pharmacodynamics of biotech drugs: principles and case studies in drug development. Wiley-VCH, Weinheim

2. Dirks NL, Nolting A, Kovar A, Meibohm B (2008) Population pharmacokinetics of cetuximab in patients with squamous cell carcinoma of the head and neck. J Clin Pharmacol 48:267-78

3. Kuester K, Kovar A, Lüpfert C, Brockhaus B, Kloft C (2008) Population pharmacokinetic data analysis of three phase I studies of matuzumab, a humanised anti-EGFR monoclonal antibody in clinical cancer development. Br J Cancer 98:9006

4. Mould DR, Sweeney KRD (2007) The pharmacokinetics and pharmacodynamics of monoclonal antibodies-mechanistic modeling applied to drug development. Curr Opin Drug Discov Devel 10:84-96

5. Kloft C, Graefe EU, Tanswell P, Scott AM, Hofheinz R, Amelsberg A, Karlsson MO (2004) Population pharmacokinetics of sibrotuzumab, a novel therapeutic monoclonal antibody, in cancer patients. Invest New Drugs 22:3952

6. Lammerts van Bueren JJ, Bleeker WK, Bøgh HO, Houtkamp M, Schuurman J, van de Winkel JGJ, Parren PWHI (2006) Effect of target dynamics on pharmacokinetics of a novel therapeutic antibody against the epidermal growth factor receptor: implications for the mechanisms of action. Cancer Res 66:7630-8

7. Mager DE, Jusko WJ (2001) General pharmacokinetic model for drugs exhibiting target-mediated drug disposition. J Pharmacokinet Pharmacodyn 28:507-32

8. Gibiansky L, Gibiansky E, Kakkar T, Ma P (2008) Approximations of the target-mediated drug disposition model and identifiability of model parameters. J Pharmacokinet Pharmacodyn 35: 573-591

9. Gibiansky L, Gibiansky E (2009) Target-mediated drug disposition model: relationships with indirect response models and application to population PK-PD analysis. J Pharmacokinet Pharmacodyn 36:341-351

10. Hood L, Perlmutter RM (2004) The impact of systems approaches on biological problems in drug discovery. Nat Biotechnol 22:1215-7

11. Kitano H (2007) A robustness-based approach to systems-oriented drug design. Nat Rev Drug Discov 6:202-10

12. Kreeger PK, Lauffenburger DA (2010) Cancer systems biology: a network modeling perspective. Carcinogenesis 31:2-8

13. Chen WW, Schoeberl B, Jasper PJ, Niepel M, Nielsen UB, Lauffenburger DA, Sorger PK (2009) Input-output behavior of ErbB signaling pathways as revealed by a mass action model trained against dynamic data. Mol Syst Biol 5:239

14. Schoeberl B, Pace EA, Fitzgerald JB, Harms BD, Xu L, Nie L, Linggi B, Kalra A, Paragas V, Bukhalid R, Grantcharova V, Kohli N, West KA, Leszczyniecka M, Feldhaus MJ, Kudla AJ, Nielsen UB (2009) Therapeutically targeting ErbB3: a key node in ligand-induced activation of the ErbB receptor-PI3K axis. Sci Signal 2:ra31

15. van der Graaf PH, Benson N (2011) Systems pharmacology: bridging systems biology and pharmacokinetics-pharmacodynamics (PKPD) in drug discovery and development. Pharm res 28:1460-1464

16. Jakobovits A, Amado R, Yang X, Roskos L, Schwab G (2007) From XenoMouse technology to panitumumab, the first fully human antibody product from transgenic mice. Nat Biotechnol 25:1134-1143

17. Mendelsohn J (2003) Status of epidermal growth factor receptor antagonists in the biology and treatment of cancer. J Clin Oncol 21:2787-2799

18. Fujita KA, Toyoshima Y, Uda S, Ozaki YI, Kubota H, Kuroda S (2010) Decoupling of receptor and downstream signals in the Akt pathway by Its low-pass filter characteristics. Sci Signal 3:ra56

19. Shankaran H, Resat H, Wiley HS (2007) Cell surface receptors for signal transduction and ligand transport: a design principles study. PLoS Comput Biol 3:e101
20. Starbuck C, Lauffenburger DA (1992) Mathematical model for the effects of epidermal growth factor receptor trafficking dynamics on fibroblast proliferation responses. Biotechnol Prog $8: 132-43$

21. Shankaran H, Wiley HS, Resat H (2007) Receptor downregulation and desensitization enhance the information processing ability of signalling receptors. BMC Syst Biol 1:48

22. Hendriks BS, Orr G, Wells A, Wiley HS, Lauffenburger DA (2005) Parsing ERK activation reveals quantitatively equivalent contributions from epidermal growth factor receptor and HER2 in human mammary epithelial cells. J Biol Chem 280:6157-6169

23. Hendriks BS, Opresko LK, Wiley HS, Lauffenburger DA (2003) Quantitative analysis of HER2-mediated effects on HER2 and epidermal growth factor receptor endocytosis: distribution of homo- and heterodimers depends on relative HER2 levels. J Biol Chem 278:23343-23351

24. Hendriks BS, Opresko LK, Wiley HS, Lauffenburger DA (2003) Coregulation of epidermal growth factor receptor/human epidermal growth factor receptor 2 (HER2) levels and locations: quantitative analysis of HER2 overexpression effects. Cancer res 63:1130-1137

25. Bleeker WK, Lammertsvan Bueren JJ, van Ojik HH, Gerritsen AF, Pluyter M, Houtkamp M, Halk E, Goldstein J, Schuurman J, van Dijk MA, van de Winkel JGJ, Parren PWHI (2004) Dual mode of action of a human anti-epidermal growth factor receptor monoclonal antibody for cancer therapy. J Immunol 173:4699-707

26. Bastholt L, Specht L, Jensen K, Brun E, Loft A, Petersen J, Kastberg H, Eriksen JG (2007) Phase I/II clinical and pharmacokinetic study evaluating a fully human monoclonal antibody against EGFr (HuMax-EGFr) in patients with advanced squamous cell carcinoma of the head and neck. Radiother Oncol 85:24-8

27. Tang L, Persky A, Hochhaus G, Meibohm B (2004) Pharmacokinetic aspects of biotechnology products. J Pharm Sci 93: 2184-2204

28. Krippendorff BF, Kuester K, Kloft C, Huisinga W (2009) Nonlinear pharmacokinetics of therapeutic proteins resulting from receptor mediated endocytosis. J Pharmacokinet Pharmacodyn 36:239-60

29. Knauer DJ, Wiley HS, Cunningham DD (1984) Relationship between epidermal growth factor receptor occupancy and mitogenic response. Quantitative analysis using a steady state model system. J Biol Chem 259:5623-31

30. Brzeziński J, Lewiński A (1998) Increased plasma concentration of epidermal growth factor in female patients with non-toxic nodular goitre. Eur J Endocrinol 138:388-93

31. Masui H, Castro L, Mendelsohn J (1993) Consumption of EGF by A431 cells: evidence for receptor recycling. J Cell Biol 120:85-93

32. Lin C, Chen W, Kruiger W, Stolarsky L, Weber W, Evans R, Verma I, Gill G, Rosenfeld M (1984) Expression cloning of human EGF receptor complementary DNA: gene amplification and three related messenger RNA products in A431 cells. Sci Agric 224:843-8

33. Ullrich A, Ullrich A, Coussens L, Coussens L, Hayflick JS, Hayflick JS, Dull TJ, Dull TJ, Gray A, Gray A, Tam AW, Tam AW, Lee J, Lee J, Yarden Y, Yarden Y, Libermann TA, Libermann TA, Schlessinger J, Schlessinger J et al (1984) Human epidermal growth factor receptor cDNA sequence and aberrant expression of the amplified gene in A431 epidermoid carcinoma cells. Nature 309:418-425

34. Reddy CC, Wells A, Lauffenburger DA (1994) Proliferative response of fibroblasts expressing internalization-deficient epidermal growth factor (EGF) receptors is altered via differential EGF depletion effect. Biotechnol Prog 10:377-84

35. Peipp M, Dechant M, Valerius T (2008) Effector mechanisms of therapeutic antibodies against ErbB receptors. Curr Opin Immunol 20:436-43 
36. Morell A, Terry W, Waldmann T (1970) Metabolic properties of IgG subclasses in man. J Clin Invest 49:673-680

37. Yang X, Jia X, Corvalan J, Wang P, Davis C (2001) Development of ABX-EGF, a fully human anti-EGF receptor monoclonal antibody, for cancer therapy. Crit Rev Oncol Hematol 38:17-23

38. Sargent ER, Gomella LG, Belldegrun A, Linehan WM, Kasid A (1989) Epidermal growth factor receptor gene expression in normal human kidney and renal cell carcinoma. J Urol 142: 1364-8

39. Ogiso Y, Oikawa T, Kondo N, Kuzumaki N, Sugihara T, Ohura T (1988) Expression of proto-oncogenes in normal and tumor tissues of human skin. J Invest Dermatol 90:841-4

40. Sakai K, Mori S, Kawamoto T, Taniguchi S, Kobori O, Morioka Y, Kuroki T, Kano K (1986) Expression of epidermal growth factor receptors on normal human gastric epithelia and gastric carcinomas. J Natl Cancer Inst 77:1047-52

41. van der Laan BF, Freeman JL, Asa SL (1995) Expression of growth factors and growth factor receptors in normal and tumorous human thyroid tissues. Thyroid 5:67-73

42. Henzen-Logmans SC, van der Burg ME, Foekens JA, Berns PM, Brussée R, Fieret JH, Klijn JG, Chadha S, Rodenburg CJ (1992) Occurrence of epidermal growth factor receptors in benign and malignant ovarian tumors and normal ovarian tissues: an immunohistochemical study. J Cancer Res Clin Oncol 118:303-307

43. Terada T, Ohta T, Nakanuma Y (1994) Expression of transforming growth factor-alpha and its receptor during human liver development and maturation. Virchows Archiv Int J Pathol 424:669-675

44. Mendelsohn J (2002) Targeting the epidermal growth factor receptor for cancer therapy. J Clin Oncol 20:1S-13S

45. Grandis JR, Melhem MF, Gooding WE, Day R, Holst VA, Wagener MM, Drenning SD, Tweardy DJ (1998) Levels of TGFalpha and EGFR protein in head and neck squamous cell carcinoma and patient survival. J Natl Cancer Inst 90:824-32

46. Merlino G, Xu Y, Ishii S, Clark A, Semba K, Toyoshima K, Yamamoto T, Pastan I (1984) Amplification and enhanced expression of the epidermal growth factor receptor gene in A431 human carcinoma cells. Science 224:417

47. Rao BM, Lauffenburger DA, Wittrup KD (2005) Integrating celllevel kinetic modeling into the design of engineered protein therapeutics. Nat Biotechnol 23:191-4

48. Crombet T, Osorio M, Cruz T, Roca C, del Castillo R, Mon R, Iznaga-Escobar N, Figueredo R, Koropatnick J, Renginfo E, Fernández E, Alvárez D, Torres O, Ramos M, Leonard I, Pérez R, Lage A (2004) Use of the humanized anti-epidermal growth factor receptor monoclonal antibody h-R3 in combination with radiotherapy in the treatment of locally advanced head and neck cancer patients. J Clin Oncol 22:1646-54

49. Carter P (2001) Improving the efficacy of antibody-based cancer therapies. Nat Rev Cancer 1:118-129

50. Messersmith W, Hidalgo M (2007) Panitumumab, a monoclonal anti epidermal growth factor receptor antibody in colorectal cancer: Another one or the one?. Clin Cancer Res 13:4664

51. Talavera A, Friemann R, Gómez-Puerta S, Martinez-Fleites C, Garrido G, Rabasa A, López-Requena A, Pupo A, Johansen RF, Sánchez O, Krengel U, Moreno E (2009) Nimotuzumab, an antitumor antibody that targets the epidermal growth factor receptor, blocks ligand binding while permitting the active receptor conformation. Cancer res 69:5851-5859

52. Lacouture ME (2006) Mechanisms of cutaneous toxicities to EGFR inhibitors. Nat Rev Cancer 6:803-12

53. Peréz-Soler R, Saltz L (2005) Cutaneous adverse effects with HER1/EGFR-targeted agents: is there a silver lining?. J Clin Oncol 23:5235-46

54. Agoram B (2007) Use of pharmacokinetic/pharmacodynamic modelling for starting dose selection in first-in-human trials of high-risk biologics. Br J Clin Pharmacol 67:53-160

55. Thurber GM, Schmidt MM, Wittrup KD (2008) Antibody tumor penetration: transport opposed by systemic and antigen-mediated clearance. Adv Drug Deliv Rev 60:1421-1434

56. Thurber G, Schmidt M, Wittrup KD (2008) Factors determining antibody distribution in tumors. Trends Pharm Sci 29:57-61

57. Urva S, Yang V, Balthasar J (2009) Physiologically based pharmacokinetic model for T84.66: a monoclonal anti-CEA antibody. J Pharm Sci :1-19

58. Davda JP, Jain M, Batra SK, Gwilt PR, Robinson DH (2008) A physiologically based pharmacokinetic (PBPK) model to characterize and predict the disposition of monoclonal antibody CC49 and its single chain $\mathrm{Fv}$ constructs. Int Immunopharmacol 8:401-13

59. Schoeberl B, Eichler-Jonsson C, Gilles ED, Mueller G (2002) Computational modeling of the dynamics of the MAP kinase cascade activated by surface and internalized EGF receptors. Nat Biotechnol 20:370-5

60. Borisov N, Aksamitiene E, Kiyatkin A, Legewie S, Berkhout J, Maiwald T, Kaimachnikov NP, Timmer J, Hoek JB, Kholodenko BN (2009) Systems-level interactions between insulin-EGF networks amplify mitogenic signaling. Mol Syst Biol 5:256

61. Kholodenko BN (2006) Cell-signalling dynamics in time and space. Natl Rev Mol Cell Biol 7:165-76 